\title{
Maldição de sísifo: retrato sem retoque de uma instituição sexagenária, periodicamente desafiada a se reinventar ${ }^{1}$
}

The sisifo's curse: portrait of an institution challenged to periodically recreat itself

JoSÉ MARQUES DE MELO Professor Emérito da ECA-USP. Diretor-Titular da Cátedra Unesco/Metodista de Comunicação, Presidente da INTERCOM e Sócio Benemérito da SBPJOR. marquesmelo@uol.com.br

\begin{abstract}
Resumo
Inventário retrospectivo dos 60 anos de ensino de jornalismo no Brasil, no quadro mundial desse campo do conhecimento. Apesar da fundação tardia, as escolas de jornalismo lograram constituir uma matriz pedagógica de natureza crítico-experimental, hibridizando os modelos europeu e norte-americano. Nesta conjuntura, a área está sendo desafiada, frente às mutaçōes tecnológicas e às transformaçōes político-culturais, a se reinventar. 0 autor sugere dois eixos para essa mudança radical: superar a tradição gutenbergiana (hegemonia da mídia impressa) e ultrapassar a caricatura balzaquiana (agenda elitista e código excludente). Propōe, ademais, a inclusāo das maiorias iletradas e dos contingentes escassamente educados no mercado consumidor dos produtos noticiosos, através da otimização das novas tecnologias de difusão simbólica, potencializando imagem e som, sem evidentemente descuidar da expressão verbal.
\end{abstract}

Palavras-chave: jornalismo, pedagogia, história, Brasil, século XX.

\section{Fundação tardia}

Há pelo menos um século a educação dos jornalistas vem constituindo desafio crucial para a sociedade brasileira.

A idéia floresceu no caldo de cultura gerado pela transformação da imprensa, quando os jornais substituíram os utensílios artesanais pelo maquinário industrial, atrelado a uma linha de produção que não deixava margem para improvisação e amadorismo.

As organizações jornalísticas deixavam de ser correias de transmissão dos partidos políticos para se converter em empresas auto-sustentáveis. $\mathrm{Na}$ contingência de fabricar notícias e comentários, sintonizados com as demandas do público leitor, elas precisavam de profissionais competentes.

Onde formá-los? Na universidade, era a resposta óbvia. Embora não faltassem pessoas para defender a formação em serviço.
Explicitada desde 1908, quando Gustavo de Lacerda fundou a ABI e reiterada enfaticamente em 1918, por João Guedes de Mello, que presidiu o I Congresso Brasileiro de Jornalistas, aquela reivindicação somente seria acolhida pelo Governo Federal vinte anos depois. Getúlio Vargas oficializou, em 1938, o ensino de jornalismo no sistema educacional brasileiro.

Isso ocorre num momento em que a idéia de formar jornalistas na academia ainda não lograra consenso no conjunto da sociedade. A primeira experiência universitária em nosso campo mostrou-se efêmera. Ao criar a Universidade do Distrito Federal, em 1935, Anísio Teixeira abriu suas portas às profissões emergentes. Uma Cátedra de Jornalismo, sob a tutela do eminente jornalista Costa Rego, chegou a ser instalada. Mas a iniciativa suscitou polêmica no interior da corporação jornalística. Tanto assim que apenas 3 alunos se matricularam nes-
Conferência proferida na abertura do $X$ Encontro Nacional dos Professores de Jornalismo. Goiânia, Universidade Federal de Goiás, 27 de abril de 2007. 
sa carreira. Um deles foi Prudente de Moraes Neto, mais tarde um dos próceres da categoria, chegando a presidir a ABI. Com o fechamento da UDF, em 1939, pelo ditador Vargas, esse embrião do ensino superior de jornalismo foi abortado.

Mas a demanda pela formação sistemática de jornalistas mostrava-se latente na sociedade brasileira. Tanto assim que, em 1943, quando lançou um Curso Livre de Jornalismo, em São Paulo, Vitorino Prata Castelo Branco encontra muita receptividade por parte dos jovens que pretendiam ser jornalistas profissionais. Arrojado e inovador, porque contemplava duas modalidades - o ensino presencial (aulas ministradas no auditório da Associação Paulista de Imprensa) e o ensino a distância (curso por correspondência), o projeto de Castelo Branco esbarra no corporativismo dos jornalistas paulistas, que reagem com truculência.

Lideranças do sindicato dos jornalistas usam o poder de influência que possuíam junto ao aparato policial, denunciando o professor responsável como charlatão. Intimidado a depor e atemorizado pela perseguição sofrida, inclusive as ofensas veiculadas pela imprensa e radiodifusão, Vitorino capitula, desativando o Curso Livre. Dele só restou a memória, porque em 1945 o autor reuniu todas as aulas num só volume, que edita por conta própria, fora do mercado livreiro, discretamente comercializado pelo sistema de reembolso postal.

\section{A legitimação conquistada}

As portas da universidade só seriam abertas ao ensino regular do Jornalismo na conjuntura do pós-guerra, quando a industrialização nacional atingia o ápice. $\mathrm{O}$ processo de substituição de importações, motivando o aparecimento de um novo ramo a indústria cultural - cuja dianteira é ocupada pelas empresas jornalísticas. Então, a demanda por jornalistas de nível universitário passou a ser alavancada pelos empresários, cujo poder de persuasão junto ao Estado mostrou-se eficaz. Rapidamente o Ministério da Educação regulamenta a legislação vigente, possibilitando a implantação das primeiras unidades de ensino.

A pioneira Escola de Jornalismo Cásper Líbero, instalada em 1947, na cidade de São Paulo, por iniciativa do jornal A Gazeta, funcionou inicialmente em convênio com a Pontifícia Universidade Católica de São Paulo. Por sua vez, o primitivo Curso de Jornalismo do Rio de Janeiro, reivindicado pela $A B I$ desde 1918, só foi criado em 1948, vinculado à Universidade do Brasil, hoje conhecida como Universidade Federal do Rio de Janeiro.

Em ambos os casos, a carreira de jornalismo foi incluída como curso dependente da Faculdade de Filosofia, Ciências e Letras, instituição formadora de quadros para o magistério secundário. Essa subordinação causou evidentes distorções no plano curricular, pela prevalência das matérias humanísticas e pequena ênfase ao ensino profissional, frustrando as primeiras turmas.

A autonomia didática foi conquistada a duras penas na década de 60 , projetando-se até os anos 70, quando surgiram faculdades ou cursos de jornalismo. Esse foi um período de grande maturação, quando pontes duradouras foram estabelecidas com os sindicatos e as empresas.

Mas, nos anos 80 , essa questão da liberdade didática voltou a ser um obstáculo. Apesar de fazer parte integrante das novas Faculdades de Comunicação, essa carreira ficou atrelada como habilitação do novo Curso de Comunicação Social. Um ciclo básico geral 
tornou a travessia penosa para os estudantes, que reagiam dentro dos limites permitidos, inclusive desistindo da carreira jornalística.

A situação só veio a ser contornada na década seguinte, quando o "ciclo básico" foi substituído pelo "tronco comum", permitindo que os alunos iniciassem o contato com a profissão desde o momento de adentrar a sala de aula. Restava, ainda, a "camisa de força” representada pelo "currículo mínimo", finalmente abolido pela nova Lei da Reforma Universitária, que, ao mesmo tempo, outorgava autonomia às universidades e instaurava a liberdade curricular para os cursos superiores. Estes passaram a organizar currículos sintonizados com as demandas do mercado e as aspirações da sociedade.

Apesar disso tudo, a experiência acumulada na formação universitária de jornalistas, permitiu ao Brasil construir uma matriz pedagógica que lhe confere identidade no panorama mundial. Mesclando o padrão europeu (ensino teórico) com o modelo americano (aprendizagem pragmática), logramos uma via crítico-experimental que está em processo de aperfeiçoamento.

Os jornalistas hoje diplomados nas instituições de qualidade possuem competência suficiente para ocupar postos de trabalho nas redações das empresas do ramo. Sua formação para o mercado se dá em laboratórios e agências experimentais. Sua preparação para o exercício da cidadania responsável transcorre em aulas e seminários que ensinam a pensar, conduzindo à aprendizagem permanente.

É um sistema perfeito? Absolutamente não. Mas pode ser melhorado. Falta uma maior interação com o mercado e a sociedade. $\mathrm{O}$ restabelecimento do estágio ajudaria a refinar o treinamento profissional. O controle da qualidade do ensino pela corporação jornalística, mediado pelo governo, poderia separar o joio do trigo, colocando em quarentena as "fábricas de diploma” (escolas de baixo nível).

\section{Batalhas remanescentes}

Enquanto celebramos, em território nacional, os 60 anos do ensino de jornalismo, no espaço internacional ocorrem eventos assinalando o centenário dessa área de conhecimento. A primeira escola de jornalismo foi criada em Paris, em 1899, por iniciativa do patronato jornalístico francês, mas os ianques se orgulham ao lembrar que as primeiras escolas de jornalismo dentro da universidade surgiram em território norte-americano. A Universidade de Missouri instalava, em 1908, a primeira escola de graduação (bacharelado), da mesma forma que a Universidade de Columbia implantaria a primeira escola de pós-graduação (mestrado) em 1912 .

Desde então, contabilizamos um saldo positivo na formação universitária de jornalistas em todo o mundo. As gerações que atuam hoje no front noticioso são mais competentes e versáteis que as engajadas há um século (nos países metropolitanos) e meio século (na periferia americana).

Mas não podemos deixar de reconhecer que estamos assistindo ao esgotamento de um ciclo profissional e o agravamento de uma conjuntura acadêmica.

Por isso mesmo, os educadores dos jornalistas precisam atentar para as mudanças de paradigmas. $\mathrm{O}$ jornalismo adquiriu maior complexidade, principalmente em função da convergência midiática e dos constantes avanços tecnológicos. No mundo acadêmico, o espaço jornalístico ainda enfrenta a batalha pela legitimação enquanto área do saber, permanecendo 
2 Doutor em Ciências da Comunicação pela Universidade de Santiago de Compostela (Galícia, Espanha), vem se destacando como um dos ativos e produtivos pesquisadores da área do Jornalismo em Portugal. Autor de uma dezena de livros, que circulam largamente nos países lusófonos, destacando-se entre eles o tratado "Elementos de Teoria e Pesquisa da Comunicação e dos Media" (2. ed., 2006). Especificamente sobre jornalismo, publicou estudos teóricos - "As notícias e seus efeitos" (2000) e "Teoria da Notícia e do Jornalismo" (2002) - compêndios didáti$\cos$ - "Introdução à análise do discurso jornalístico impresso" (2004) e "Elementos de Jornalismo Impresso" (2005), análise de análises históricas - "História Crítica del Fotoperiodismo 0ccidental" (2003) e "Fotojornalismo" (2004). Dedica-se atualmente a um alentado projeto de resgate da gênese do jornalismo português.

3 Evento promovido periodicamente pelo Centro de Estudos da Comunicação da Universidade Fernando Pessoa, Porto, Portugal. 0 primeiro foi realizado em 2006 e 0 segundo em 2007.

4 Vide, a propósito, 0 artigo de Mário Mesquita - A educação para o Jornalismo: uma perspectiva sobre Portugal", Intercom Revista Brasileira de Ciências da Comunicação, 17:2 (1994): 75-97. vivas as tensões entre teoria e prática. Em conseqüência, é urgente repensar completamente o ensino de jornalismo para sintonizá-lo com as demandas do novo século.

Precisamos vencer a secular batalha pela inclusão cognitiva das maiorias incultas e iletradas que povoam o território nacional. Apesar de depauperadas economicamente, elas são detentoras de um patrimônio cultural enraizado nas tradições orais e audiovisuais das nossas classes subalternas. Não podemos continuar a ignorá-lo ou menosprezá-lo.

Sabemos que a solução do problema é muito complexa. Mas, enquanto não houver empregos suficientes, integrando à sociedade de consumo todos os marginalizados. Enquanto faltar escola de boa qualidade, elevando o nível cultural das novas geraçōes, temos um dever a cumprir.

Trata-se de criar e experimentar formatos jornalísticos que potencializem as novas tecnologias. E que sejam capazes de catalisar o saber popular, repartindo os conhecimentos destinados a estimular o apetite cognitivo dos que estão à margem da cultura impressa.

\section{Obstáculos a superar}

Mas não é suficiente fazer proposições. Se queremos transformá-las em realidades concretas, necessitamos refletir sobre o contexto histórico para discernir os impasses da atualidade.

Nesse sentido é que retomamos o paradoxo motivador do recente colóquio internacional sobre a educação dos jornalistas, cujo cenário foi a cidade do Porto, em março deste ano, tendo como tema central a pergunta-chave: "Por que estudar jornalismo?".

Todos os participantes se questionavam: Por que incluir, na agenda do século XXI, a mesma pergunta que aflorou vigorosamente, tanto na Europa quando na América, no início do século passado?

$\mathrm{O}$ argumento usado pelo Professor Jorge Pedro Sousa, ${ }^{2}$ coordenador das atrativas Jornadas Internacionais de Jornalismo, ${ }^{3}$ foi convincente. Ele está ancorado na persistência de dois flancos naquela batalha cotidiana para legitimar nossa área de trabalho perante a sociedade e dentro da universidade.

O flanco externo é representado pelo conflito ostensivo entre os acadêmicos e os profissionais. A questão foi enunciada propositivamente: "É tempo de a Academia e os profissionais deixarem de andar de costas voltadas". A solução está na abertura de uma simples rua de mão dupla: "É preciso atrair os jornalistas à Universidade, tal como é preciso franquear o acesso dos órgãos jornalísticos aos investigadores." (Souza, 2007).

O flanco interno é simbolizado pela competição, ora sutil, ora agressiva, entre os jornalistas adventícios e os acadêmicos apoderados, disputando hegemonias universitárias. Sem meias palavras, nosso anfitriāo lusitano manifestava o temor de que "o Jornalismo e os estudos jornalísticos (...) sejam descaracterizados no seio das Ciências da Comunicação", defendendo "a especificidade do Jornalismo, como atividade que procura descrever a realidade com determinados métodos e técnicas e que gera um tipo particular de conhecimento sobre ela." (Souza, 2007).

Confesso que o desafio lançado pelo colega português poderia denotar anacronismo ou conotar uma singularidade lusitana pelo ingresso tardio de Portugal no campo. ${ }^{4}$ Mas basta fazer breve revisão da literatura recente sobre jornalismo para perceber a atualidade e a oportunidade deste fórum.

Diagnósticos assinados por autores tão díspares como o alemão Kunczik 
(1997), o italiano Bechelloni (1995), os franceses Neveu (2006) e Huellan (2004), os espanhóis Cascais (2004) e Diezhandino (1994), os norte-americanos Hachten (1998) e Reese (2001), os portugueses Pinto (2004) e Fidalgo (2004) ou os brasileiros Meditsch (2004), Pena (2005) e Machado (2003) reconhecem inequivocamente a existência de uma crise de identidade do jornalismo num cenário de incertezas.

\section{A tradição da crise}

Trata-se, em verdade, de crise cíclica, periodicamente vivenciada pela nossa categoria. Por isso mesmo, as lideranças jornalísticas, estigmatizadas pela maldição de Sísifo, ${ }^{5}$ precisam regressar constantemente ao espaço público. Sua tarefa é fazer a defesa da nossa legitimidade enquanto grupo profissional e da nossa especificidade como campo acadêmico.

O mais contundente libelo contra o jornalismo e os jornalistas, refletindo a conjuntura da imprensa, durante o processo de massificação das tiragens e conseqüente mercantilização editorial, data de 1843. Seu autor: o romancista francês Honoré de Balzac, que tão bem retratou as agruras da "comédia humana". Sua motivação: catalisar o ressentimento dos escritores notáveis que começavam a perder espaço para os emergentes jornalistas. Suas armas de combate: a ironia, a sátira, a caricatura.

$\mathrm{Na}$ conclusão da "Monografia da Imprensa Parisiense", Balzac lança dois axiomas. $\mathrm{O}$ primeiro focaliza a natureza controvertida do relato jornalístico: "Para o jornalista, tudo que é provável é verdadeiro". O segundo traduz o sentimento aristocrático da intelectualidade francesa: "Se a imprensa não existisse, seria preciso não inventá-la." (Balzac, 1999).

\section{Matrizes forâneas}

Não é sem razão que, no fim do século, a vanguarda da imprensa, reunida em congresso mundial (Lisboa, 1898), concita a categoria a reinventar o próprio jornalismo. Esse caminho passava pela educação dos jornalistas. Albert Bataille, fundador da primeira escola européia de jornalismo (Paris, 1899), aponta as mudanças tecnológicas como responsáveis pela mutação da nossa categoria profissional, defendendo a qualificação dos futuros praticantes do ofício (Marcos, 1987).

"Com o aperfeiçoamento das máquinas de imprimir, com o telégrafo e o telefone, com a transformação do espírito público, cada vez mais ávido de ser informado, uma metamorfose se operou no jornalismo: a polêmica foi relegada para segundo plano e a informação passou para primeiro. No dia em que essa transformação se verificou, o jornalismo converteuse numa carreira; é preciso deixar de dizer que a nossa profissão recruta os seus adeptos entre os desenganados de todas as carreiras; para chegar ao recrutamento regular, à renovação normal da imprensa, é preciso organizar os quadros de reserva e tornar menos penosos os anos de aprendizagem aos jovens que se sintam com vocação; e para isso é necessário que a educação geral se complete com a educação profissional".

Do lado de cá do Atlântico, Joseph Pulitzer, mecenas que financiou a primeira escola pós-graduada em jornalismo, na Universidade de Columbia, cidade de Nova Iorque (1912), enfrentava a miopia daqueles que patrocinavam a tese: "os jornalistas estão convencidos de ser como os poetas: born, not made". Refutando calorosamente a premissa, ele argumentava: "a única posição a que um homem pode triunfalmente atingir pelo simples fato de ter nascido é a de idiota; para qual-
5 A rotina jornalística impõe aos praticantes do ofício o recomeço diário do trabalho de apuração, coleta. seleção e difusão das notícias, tal qual Sísifo, o personagem da mitologia grega condenado a rolar uma pedra até 0 cume da montanha, refazendo a jornada, dia após dia, sem cessar. Morris, William - The American Heritage Dictionary, Boston, Houghton, 1973, p. 1210. 
quer outra, some training is required". E concluía de modo categórico, justapondo ética e técnica: "É o jornalismo a mais exata das profissōes, a que requer o conhecimento mais largo e profundo e os mais firmes fundamentos de caráter." (Rizzini, 1953).

Entretanto, desde 1908, funcionava na Universidade de Missouri aquela que seria a escola-modelo para todo o continente americano. Legatária do pragmatismo cultivado pelos educadores progressistas, a preparação jornalística experimentada por Walter Williams temperou humanismo e profissionalismo.

O campus oferecia amplo leque de opções para nutrir a bagagem cognitiva dos futuros jornalistas, mas o cerne da formação estava no jornal-laboratório. Tal qual faziam os médicos no hospital-escola, sob a orientação de esculápios-educadores, diagnosticando e clinicando, os repórteres em treinamento produziam diariamente o University Missourian. Esse jornal circulava na comunidade, subsidiado pelo mercado local. Além de atuar como instrutores (dando aulas práticas), os jornalistas-professores ministravam aulas teóricas (seminários) sobre a profissão, motivadas pelas questões éticas ou técnicas suscitadas durante o processo de produção noticiosa (Williams, 1929).

No princípio, a universidade cumpriu a função de treinar jornalistas para atender às demandas da sociedade, em plena sintonia com o mercado de trabalho. Mas logo depois, ela se converteu em espaço de produção de conhecimento jornalístico, desenvolvendo pesquisas sobre os fenômenos decorrentes da circulação das notícias e seus comentários.

Essa nova etapa vai ser desenvolvida simultaneamente nos dois continentes. Nos Estados Unidos, sob a liderança das universidades de Wisconsin e Minnesotta, os estudos pós- graduados de jornalismo começam a dialogar com as ciências sociais. $\mathrm{Na}$ Alemanha, a construção da identidade do jornalismo toma corpo através $\mathrm{da}$ zeitungswissenchat, tendência em cuja vanguarda estão as universidades de Munster e Munich. O jornalismo passa a ser investigado cientificamente, gerando teses de mestrado e doutorado, cujos resultados se incorporam ao repertório intelectual dos futuros jornalistas. Esse conhecimento novo também serve às empresas, ao governo e aos movimentos cívicos para a tomada de decisões estratégicas (Marques de Melo, 1975).

\section{Inventividade brasileira}

A periferia atlântica vai acompanhando com muito interesse as iniciativas que germinam e florescem nos países metropolitanos. No caso emblemático do Brasil, há registros das demandas relacionadas com a formação profissional dos jornalistas, desde fins do século XIX. Entretanto, tais aspiraçôes não encontram ambiente fértil, a não ser por intermédio de cursos livres promovidos pela igreja católica ou pelas entidades corporativas dos jornalistas (Marques de Melo, 2006a).

O Estado brasileiro entra tardiamente em cena para reconhecer de fato o Jornalismo como área de estudos universitários, depois de acionado pelas empresas e pelos sindicatos. Pouco a pouco, como conseqüência da industrialização midiática, o campo cresceu, culminando com a explosão posterior à regulamentação profissional (1969), tornando obrigatório o diploma de jornalista para ingresso na carreira.

Apesar de controversa, suscitando debates acalorados e enfrentando resistências poderosas, a reserva de mercado para os jornalistas qualificados pelas universidades vigora até os dias 
de hoje. Esse fator contribuiu para o fortalecimento do ensino de jornalismo, justificando sua expansão em todo o território nacional. O INEP - Instituto de Estudos Pedagócios calcula que 443 cursos de jornalismo estão funcionando no país. Lamentavelmente, a lei do diploma favoreceu a proliferação de escolas de primeira e de segunda classe. Estas últimas ficaram acomodadas ao rito cartorial de expedir passaportes para o mercado de trabalho, sem atentar para as demandas ocupacionais, nem acumular conhecimento jornalístico.

De qualquer maneira, como afirmei anteriormente, o Brasil cunhou uma matriz didático-científica autônoma, nesses 60 anos de funcionamento regular do curso de jornalismo e nesses 30 anos de melhoria gradativa da competência pedagógica e da capacidade investigativa em instituiçôes de vanguarda. Trata-se de modelo mestiço, como o é a nossa cultura nacional, hibridizando os protótipos testados na América do Norte com as variáveis que demonstram eficácia na Comunidade Européia.

A construção dessa via brasileira para estudar o jornalismo, sedimentada no tripé - conhecer, experimentar, pesquisar - está fundamenta nas contribuições de cinco jornalistas-educadores:

1. Vitorino Prata Castelo Branco (1904-1986) produziu o primeiro manual de jornalismo do país (1943), sistematizando uma agenda mínima para a formação do universo cognitiva dos futuros jornalistas (Dias, 2005).

2. Carlos Rizzini (1898-1972) pesquisou as experiências forâneas do ensino de jornalismo, focalizando e privilegiando as alternativas norte-americanas para confrontá-las com $s$ diretrizes adotadas pela pioneira Faculdade Cásper Líbero (Rocha Dias, 2004).
3. Danton Jobim (1906-1978) realizou o primeiro inventário crítico das estratégias pedagógicas do curso de jornalismo numa universidade pública (a outrora Universidade do Brasil, hoje denominada Universidade Federal do Rio de Janeiro) e dos obstáculos para a sua implantação (Marques de Melo, 2005).

4. Pompeu de Souza (1916-1992) encarregou-se de articular o ensino de jornalismo com a estrutura peculiar a uma moderna faculdade de comunicação de massas (Universidade de Brasília) (Bars, 2006).

5. Luiz Beltrão (1918-1986), renovador do ensino de jornalismo no país, beneficiou-se da experiência acumulada pelos que o precederam, propondo um modelo integrado de ensino e pesquisa. Sua meta pedagógica era promover a interação escola/empresa/comunidade, favorecendo a aplicação de conhecimentos sintonizados com a ecologia regional para difundir conteúdos socialmente relevantes (Duarte, 2005).

\section{Matriz verde-amarela}

Esse modelo brasileiro de ensino de jornalismo foi cultivado dentro da faculdade de comunicação, onde essa habilitação profissional convive dialeticamente com suas congêneres - publicidade, relações públicas, rádio-televisão, cinema, produção editorial.

A etapa cognitiva articula-se em função de dois eixos: as matérias que fundamentam os processos de codificação e os conteúdos a serem difundidos (humanísticos, comportamentais, gerenciais, tecnológicos etc.) e as interdisciplinas que pretendem explicar os fenômenos comunicacionais ( $\mathrm{da}$ sociologia da comunicação à filosofia crítica e aos estudos culturais).

Mas o espaço privilegiado da aprendizagem está localizado nos la- 
boratórios. Ali se concretiza o pragmatismo criativo, através da aplicação das técnicas jornalísticas ou de simulações didáticas e exercícios práticos. Monitorados pelos docentes, os alunos quase sempre testam produtos que circulam e repercutem em audiências reais. A infra-estrutura laboratorial que dá sustentação à fase experimental tem sido objeto de regulamentação por parte do Estado, que avalia sua composição e disponibilidade no momento em que os cursos são credenciados.

O circuito se completa com o fomento da pesquisa, através de projetos de iniciação científica. Engajando equipes de estudantes de licenciatura, vocacionados para a vida acadêmica, quase sempre convergem para programas avançados (reservados ao mestrado e doutorado). Nas instituiçóes que não possuem cursos de pós-graduação, a pesquisa se realiza sob a égide de professores contratados em regimes especiais, agraciados com tempo extra-aula para o desenvolvimento de projetos destinados à produção ou à divulgação de novos conhecimentos.

Desta maneira, o estudo do jornalismo vem se desenvolvendo no Brasil.

\section{Reinvenção inadiável}

Uma pergunta ficou no ar, suscitando resposta imediata: o modelo atende às aspirações nacionais nesta conjuntura de acelerada mutação tecnológica e de transformações velozes nos processos de produção e difusão jornalística?

Capitalizando meio século de imersão em atividades jornalísticas, desde a iniciação precoce nas rotinas profissionais, até a dedicação exclusiva ao trabalho acadêmico, minha resposta pessoal é negativa.

Tenho consciência de que o nosso ensino do jornalismo precisa ser rein- ventando para superar duas distorções congênitas:

1. Romper a tradiçãao gutenbergiana que nos tem mantido prisioneiros, dentro de estruturas tecnologicamente anacrônicas que ainda governam a lógica dos processos de ensino-aprendizagem. Precisamos potencializar os recursos oferecidos pelas novas tecnologias digitais, formando profissionais vocacionados para produzir conteúdos jornalísticos de interesse das maiorias iletradas, que permanecem excluídas do banquete civilizatório. Isso corresponde a priorizar os modos de expressão jornalística através do som e da imagem, sem evidentemente descuidar o código verbal.

2. Ultrapassar a caricatura balzaquiana que nos tem induzido a privilegiar a formação aristocrática de jornalistas, comprometidos com os interesses das elites cultas ou medianamente educadas. Precisamos engendrar estratégias discursivas sintonizadas com o repertório das populações sub-informadas e aplicar táticas motivadoras do apetite cultural daqueles bolsões marginalizados da sociedade de consumo. Do contrário, nossa Sociedade do Conhecimento será também uma caricatura, perpetuando a Sociedade dos Conhecidos (aquela que nos governa secularmente). Para tanto, precisamos tomar como referência a Cultura Popular, ao invés de persistir no domínio exclusivo da Cultura Erudita.

Como lograr essa transformação? Trata-se de compromisso que está a desafiar o espírito público da nova geração de educadores e investigadores do jornalismo que o Fórum Nacional dos Professores de Jornalismo vem reunindo há dez anos.

Cabe a esse novo segmento da comunidade acadêmica, em sintonia com o mercado e a sociedade civil, romper as muralhas do gueto uni- 
versitário, repensando o esgotamento do nosso modelo de jornalismo para incluir cognitivamente o vasto contingente que o jornalista venezuelano Eleazar Diaz Rangel rotulou apropriadamente como "pueblos subinformados".

Como diz Clovis Rossi é a "desinformação a mãe de vários outros problemas. Quem não sabe nem se interessa pelo que está acontecendo aceita passivamente a miséria e/ou a mediocridade que é o cotidiano da maioria”.

Formar profissionais capazes de superar essa situação-limite e pesquisadores engajados na produção de conhecimento empírico constitui o ponto de partida para nos libertar da servidão intelectual que nos tem condenado a mimetizar padróes estéticos e modelos culturais, sempre de costas para o legado das geraçóes que nos precederam.

\section{Resumen}

Revisión histórica de 60 años de la enseñanza de periodismo en Brasil, en el marco mundial del campo académico. Aunque desfasadas cronológicamente respecto a sus congéneres metropolitanas, nuestras escuelas de periodismo pueden celebrar la constitución de una matriz pedagógica de naturaleza crítico-experimental. En esta coyuntura, frente al reto de las mutaciones tecnológicas y de los cambios político-culturales, el área enfrenta el desafío de su reinvención. El autor propone dos ejes para obtener esa transformación radical: superar la tradición gutenbegiana (hegemonía de la prensa) y ultrapasar la caricatura balzaquiana (agenda elitista y código excluyente). Sugiere, además, la inclusión de las mayorías iletradas y de los contingentes sin educación formal suficiente para participar del mercado consumidor de productos noticiosos, a través del uso intensivo de nueva tecnologías de difusión simbólica, fomentando el sonido y la imagen, sin naturalmente olvidar las formas de expresión verbal.

Palabras-clave: periodismo, pedagogia história, Brasil, siglo XX.

\section{Abstract}

Background review of the journalism education during the last 60 years in Brazil, taking as framework the academic world. Despite its late foundation, journalism schools can celebrate the constitution of a pedagogical matrix shaped by critical-experimental patterns. In order to face technological mutations and political or cultural advances, the area is supposed to be reinvented. The author suggests two axes just to accomplish this radical change: overpass the Gutenberg tradition (hegemony of the print media patterns) and to stop the Balzac caricature (agenda-setting biased by aristocratic subjects and linguistic codes oriented by the uses of the upper classes). He also provides two immediate goals: to include the illiterate masses and the less educated people in the media audience, through the use of sound and images new technologies, naturally pay attention to the verbal forms of expression.

Key-words: journalism, education, history, Brasil, XX century.

\section{Fontes consultadas}

ATHAYDE, Ausregésilo. 1939. Os problemas do jornalismo no Brasil, Estudos Brasileiros 1:4 (1939) 19-29.

BALZAC, Honoré de. 1999. Os jornalistas, São Paulo, Ediouro.

BARS, Rosemary. 2007. Pompeu de Souza, In: MARQUES DE MELO, José. Imprensa Brasileira, 3, São Paulo, Metodista/Imprensa Oficial, no prelo.

BECHELLONI, Giovanni. 1995. Giornalismo o Postgiornalismo?, Napoli, Liguori.

CASCAIS, Fernando. 2004. O ensino do/ para o jornalismo e a formação profissional, Comunicação e Sociedade, 5, p. 79-84.

DIAS, Osni. 2005. Vitorino Prata Castelo Branco, In: Marques de Melo, José. Imprensa Brasileira, 2, São Paulo, Metodista/Imprensa Oficial, p. 199-210. 
DIAZ RANGEL, Eleazar. 1967. Pueblos sub-informados, Caracas, UCV.

DIEZHADINO, Bezunartey Coca. 1994. La elite del periodismo, Bilbao, UPV.

DUARTE, Jorge. 2005. Luiz Beltrão, In: Marques de Melo, José. Imprensa Brasileira, 2, São Paulo, Metodista/Imprensa Oficial, p. 107-118.

FIDALGO, Joaquim. 2004. Jornalistas: um perfil socioprofissional em mudança, Comunicação e Sociedade, 5, p. 63-74.

HACHTEN, William. 1998. The Troubles of Journalism, New Jersey, Lawrence.

HUELLAN, Denis. 2004. Grupo profissional e mercado de trabalho do jornalismo, Comunicação e Sociedade, 5, p. 9-24.

KUNCZIK, Michael. 1997. Conceitos de Jornalismo, norte e sul, São Paulo, Edusp. MACHADO, Elias. 2003. O ciberespaço como fonte para os jornalistas, Salvador, Calandra.

MARQUES DE MELO, José. 2007. Reinventar o ensino de jornalismo, Porto, Portugal, Palestra proferida na sessão inaugural das II Jornadas Internacionais de Jornalismo, 2 de março de 2007.

MARQUES DE MELO, José. 2006. Teoria do Jornalismo, identidades brasileiras, São Paulo, Paulus.

MARQUES DE MELO, José. 2006a. Pedagogia da Comunicação: matrizes bras., S. Paulo, Angellara.

MARQUES DE MELO, José. 2005. O pionerismo de Danton Jobim, Contracampo, 12, p. 7-22.

MARQUES DE MELO, José. 2003. Jornalismo Brasileiro, Porto Alegre, Sulina.

MARQUES DE MELO, José. 1994. Transformaçôes do jornalismo brasileiro, São Paulo, Intercom.

MARQUES DE MELO, José. 1975. Pósgrad. nos EUA, Rev. da Abepec, v. 1, n. 2, P. Alegre, p. 11-35.
MARCOS, Luis Humberto. 1987. Primeiro a inovar, último a formar, Intercom - Rev. Bras. de Comunicação, n. 57, São Paulo, p. 115-118.

MEDITSCH, Eduardo. 2004. A formação para a praxis profissional do jornalista, Comunicação e Sociedade, 5, p. 25-38.

NEVEU, Erik. 2006. Sociologia do Jornalismo, São Paulo, Loyola.

PENA, Felipe. 2005. Teoria do Jornalismo, São Paulo, Contexto.

PINTO, Manuel. 2004. O ensino e formação na área do jornalismo em Portugal, Comunicação e Sociedade, 5, p. 49-62.

REESE, S. 2001. Education for Journalism and Mass Communication in the Croassroad, Mass Communication Educator, 56/3, Autumn.

RIZZINI, Carlos. 1950. O ensino de jornalismo, Rio de Janeiro, MEC.

ROCHA DIAS, Paulo da. 2004. $O$ amigo do Rei, Florianópolis, Letras Contemporâneas.

ROSSI, Clovis. 2007. Desinformados, mas felizes, Folha de S. Paulo, 8/4/2007, p. 2.

SOUSA, Jorge Pedro. 2007. Porque estudar o jornalismo?, II Jornadas Internacionais de Jornalismo. Programa, Porto. Portugal, www.ufp.eventos.pt.

SOUSA, Jorge Pedro. 2002. Teorias da notícia e do jornalismo, Chapecó, Argos.

WILLIAMS, Sarah L. 1929. Twenty Years of the Education for Journalists, Missouri, Stephens Pub. Co.

Data do recebimento: 16/10/2007 Data do aceite: $22 / 11 / 2007$ 